\title{
ALFABETIZAÇÃO NO MÉTODO SOCIOLINGUÍSTICO: UMA PROPOSTA PARA O EXERCÍCIO DA CONSCIÊNCIA SOCIAL, SILÁBICA E ALFABÉTICA ${ }^{79}$
}

\author{
Valéria Batista* \\ Mônica Bruna Forte**
}

Resumo: O presente trabalho trata do tema da alfabetização numa perspectiva crítica e reflexiva do sujeito, sem desconsiderar a importância de princípios linguísticos básicos da fala, da escrita e da leitura como base para uma alfabetização. Tem como objetivo geral analisar o Método de Paulo Freire associado com as aplicações linguísticas das autoras Emília Ferreiro e Ana Teberosky. O presente estudo trata de uma pesquisa teórico-bibliográfica. Seus resultados indicam que para atingir esse modelo de alfabetização devemos reinventar o processo de ensino da leitura e da escrita a partir de uma perspectiva social. Nossa defesa é de que o ensino possibilita a inserção do sujeito no seu contexto social e político, na sua realidade e pode promover o despertar para a cidadania, encaminhando-o para a sua transformação social e consciência crítica, além de valorizar o domínio das correspondências entre grafemas e fonemas, para a exercitação da consciência silábica e alfabética.

Palavras-chave: Alfabetização. Método Sociolinguístico, Paulo Freire.

\begin{abstract}
This work deals with the literacy theme in a critical and reflexive perspective of the subject, without ignoring the importance of basic linguistic principles of speaking, writing and reading as a basis for literacy. It has the general objective to analyze the Paulo Freire method associated with language applications of the authors Emilia Ferreiro and Ana Teberosky. Este study is a theoretical and bibliographical research. The survey results indicate that to achieve the literacy model must reinvent the process of teaching reading and writing from a social perspective. We

\footnotetext{
79* Artigo de Iniciação Científica apresentado ao Programa de Iniciação Científica da Universidade Camilo Castelo Branco, como produto final de pesquisa teórico-bibliográfica sobre o tema abordado.

** Orientadora do Programa Institucional de Bolsa de Iniciação Científica - PIBIC 2015/2016. Doutora em Educação: Psicologia da Educação pela Pontifícia Universidade Católica de São Paulo- PUCSP, Mestra em Educação, Pós-graduada em Gestão e Organização Escolar, Pedagoga pela Universidade Cidade de São Paulo -UNICID. Coordenadora e professora de Pós-graduação nos cursos de Alfabetização e Letramento e na Educação Infantil e Cultura, professora de graduação nos cursos de Pedagogia e Filosofia no Centro Universitário Assunção-UNIFAI e Coordenadora de Educação Infantil e Ensino Fundamental I no Colégio São José do Maranhão.

*** Graduanda do Curso de Pedagogia/SP pela Universidade Camilo Castelo Branco e aluna do Programa Institucional de Bolsa de Iniciação Científica - PIBIC 2015/2016.
} 
conclude that allows the inclusion of the subject in its social and political context in its reality and can promote the awakening of this subject for citizenship forwarding it to your social transformation and critical awareness, and enhance the field of correspondences between graphemes and phonemes, for the drilling of syllabic and alphabetic awareness.

Keywords: Literacy, Sociolinguistic method, Paulo Freire.

\section{Introdução}

Os inúmeros debates em torno do tema da alfabetização apontam a grande preocupação das políticas públicas em nosso país desde o final do século XIX. Esse tema também foi palco de acirradas disputas a respeito do melhor método de alfabetização a criança. Na Proclamação da República temos o marco de um momento em que a educação ganha destaque, por conta dos ideais do Estado republicano, que traz a proposta de uma nova ordem política e social e, com isso, a universalização de ensino, a escola obrigatória, leiga e gratuita passando a estender o acesso do ensino da leitura e da escrita para todos trazendo a necessidade de termos profissionais especializados para atuar na educação. Esta, sem dúvida, foi uma revolução dos processos de ensinar na fase inicial para um novo mundo obtendo diferentes formas de relação com a natureza, com a história, ou seja, com novos modos de como pensar e agir. A escola, historicamente, sempre apresentou dificuldades de sanar os problemas de alfabetização decorrentes dos métodos de ensino, do aluno ausente, do professor sem especialização e do sistema escolar com pouca estrutura, e pensar como se dá o processo de alfabetização passa a ter um grau de importância, na medida em que se pretende compreender a história da alfabetização, suas influências e sentidos (MORTATTI, 2006).

Cagliari (1999) afirma que a alfabetização se baseia em três grandes aspectos da linguagem: a fala, a escrita e a leitura e a proposta do Método sociolinguístico; na medida em que se baseia no método de alfabetização de Paulo Freire, contempla todos esses aspectos, pois propõem passos, 'codificação' e 'decodificação', e busca transformar a consciência ingênua do alfabetizando em consciência crítica.

A questão que se pretende responder aqui: De que maneira o método de Paulo Freire, associado com as aplicações linguísticas da Psicogênese da Língua Escrita de Emília Ferreiro e Ana 
Teberosky para o processo de alfabetização, se identificam com o Método Sociolinguístico, que considera a escrita uma análise de consciência social, silábica e alfabética e pode encaminhar o sujeito à transformação social?

Os objetivos específicos desta pesquisa são: conhecer o Método de alfabetização de Paulo Freire e seus princípios; conhecer os pressupostos teóricos que dão embasamento à Psicogênese da Língua Escrita das autoras Emília Ferreiro e Ana Teberosky; associar as implicações linguísticas da Psicogênese da Língua Escrita com o Método Paulo Freire; identificar em que medida a alfabetização como um processo metacognitivo torna possível outros processos cognitivos e sociais que podem encaminhar o sujeito às transformações sociais a partir do conhecimento.

Este estudo trata de uma pesquisa teórico-bibliográfica, numa perspectiva qualitativa que possibilita a leitura da realidade. Os materiais utilizados foram livros, artigos, pesquisas acadêmicas, tendo como principais autores Paulo Freire, Onaide Schwartz Mendonça e Olympio Correa Mendonça, Ana Maria Saul, Magda Soares, Miriam Lemle, Emilia Ferreiro e Ana Teberosky.

O trabalho é composto por três seções. Na primeira, apresentaremos um estudo das publicações sobre a alfabetização, com ênfase na alfabetização sociolinguística; na segunda, abordaremos o Método Paulo Freire, e na última e terceira seção, a compreensão do método sociolinguístico que encaminha o sujeito a uma consciência silábica, alfabética, mas também social.

\section{Produções acadêmicas na alfabetização sociolinguística}

Magda Soares e Francisca Maciel têm se debruçado nos estudos sobre a produção acadêmica no que diz respeito à alfabetização. Ambas se referem ao termo alfabetização como 'estado do conhecimento. Com início nos anos de 1980 e com foco no período de 1961-1989, Soares e Maciel apresentaram três décadas de produção acadêmica entre teses e dissertações sobre o tema alfabetização. Elas organizam a publicação em quatro tópicos: no primeiro, apresentam um panorama geral da produção de teses e dissertações; no segundo, analisam as produções segundo os temas privilegiados; no terceiro, identificam e confirmam os diferentes pressupostos teóricos em que se fundamentam as dissertações e teses, e no quarto e último tópico, categorizam as dissertações e teses segundo os tipos de pesquisa escolhidos pelos autores para o desenvolvimento da investigação. 
Soares \& Maciel (2000) evidenciam um aumento significativo de pesquisas por conta do crescimento expressivo do número de Programas de Pós-graduação na década de 80 . No período que compreende os anos de 1961-1989, foi um total de 219 produções acadêmicas, sendo que na década dos anos de 1960, tínhamos duas produções, que representam 5\% das pesquisas realizadas no período; na década de 1970, ocorre um pequeno aumento, totalizando 37 produções, que representam 17\%; e na década de 1980, um total de 177 trabalhos, que representam 81\% nas produções das três décadas. As autoras destacam que nas décadas de 1960 e 1970 os estudos e as pesquisas apresentam uma perspectiva positivista e uma análise mais ampla da alfabetização. Já na década de 1980, o crescimento e a diversificação nas produções acadêmicas sobre alfabetização se dão em várias modalidades de pesquisa, exceto a Pesquisa Histórica, fruto de apenas um trabalho realizado na década de 1970; mas as demais modalidades crescem mais de 50\% (SOARES; MACIEL, 2000, p. 61).

Para este artigo destacamos, no documento produzido pelas autoras Soares \& Maciel (2000), destacamos quatro dissertações na área do mestrado sob perspectiva sociolinguística das seguintes autoras: Guimarães (1979) - “A validade da mensagem nas classes de alfabetização"; Nozaki (1986): “Código e desigualdade: estudo experimental de sociolinguística aplicado à tecnologia educacional”; Balarini (1987) - “Alfabetização: uma interpretação sociolinguística”; e Silva (1987) - "Para repensar a alfabetização: um estudo introdutório".

Guimarães (1979) verificou as relações entre a linguagem da escola e a de alunos culturalmente diversificados e a existência de diferenças que possam constituir obstáculo à eficácia do desempenho escolar em leitura e escrita. Na dissertação, a autora trabalhou com os pressupostos e conceitos a respeito do processo de comunicação, da teoria do sinal linguístico e do conhecimento já construído sobre as variáveis que interferem no desempenho do usuário do código linguístico. E concluiu que a escola entende a iniciação à escrita como aquisição da mecânica associativa entre sons da língua e grafias; faltam informações suficientes sobre a competência comunicativa das crianças, sobretudo as das camadas populares.

Nozaki (1986) identificou os efeitos de um programa de treinamento de linguagem no desempenho de alunos de $1^{\text {a }}$ série, socialmente desfavorecidos, e detectou, na aplicação desse programa, elementos diferenciais no uso da linguagem determinados pelo contexto. Os sujeitos da pesquisa foram dois grupos de crianças (grupo experimental e grupo controle) em fase de alfabetização de uma escola municipal do Rio de Janeiro situada em área de favela. Os grupos 
foram submetidos a pré e pós-teste. As análises dos resultados indicaram a eficácia do programa e a possibilidade de seu uso na construção de um programa tecnológico curricular para o ensino no préescolar, o que implica na necessidade de elaboração de um projeto de treinamento técnico para professores.

Balarini (1987) trabalhou com a distância entre a variedade linguística utilizada pela escola para ensinar a língua escrita e a variedade linguística utilizada pelo aluno, objetivando estudar o processo de alfabetização, do ponto de vista da Sociolinguística. Desenvolvida numa escola estadual de Vitória com alto índice de reprovação, a pesquisa buscou compreender como se relacionavam as características linguísticas do dialeto do aluno com as características linguísticas do material didático usado na alfabetização, sob o ponto de vista sintático, verificando se ocorriam bloqueios na interação criança/texto escrito. A autora concluiu que a escrita infantil não reproduz a fala, mas reflete a cartilha; a escola inibe e desestimula a criança no sentido de que esta se aproprie da escrita para dela fazer outros usos além do escolar; o bloqueio entre a criança e a escrita é resultado do controle da linguagem e de formas de comportamento social; a alfabetização fundamenta-se numa concepção mecanicista de língua; o continuum fala/escrita é interrompido pela ação alfabetizadora, e a língua escrita é artificializada; o processo leva a criança ao sentimento de que é desagradável escrever. A autora afirma que o modelo de língua escrita oferecido pela escola tem papel decisivo na produção escrita infantil.

Silva (1987) teve como objetivo analisar como é encarada, na escola, a maneira de falar da criança de camadas populares e suas implicações para a aprendizagem da leitura e da escrita. Também buscou verificar a utilização ou não das experiências da criança pela escola e descrever como ocorre, em sala de aula, o ensino da leitura e da escrita. Constatou, nas professoras, a presença de preconceitos em relação à fala das crianças e as interações linguísticas escolares funcionando como forma de dominação, o que reforça as diferenças sociais; nas crianças, a utilização da linguagem como forma de resistência, de manutenção de sua identificação cultural com o seu meio; nas atividades de ensino-aprendizagem, uma desarticulação entre as experiências de vida das crianças e o conteúdo que a escola lhes impõe, e um ensino da leitura e da escrita restrito a exercícios mecânicos de repetição e cópia. Concluindo, a autora sugere alternativas para o processo de alfabetização na escola. 


\section{ALFABETIZAÇÃO NO MÉTODO SOCIOLINGUÍSTICO: UMA PROPOSTA PARA O EXERCÍCIO DA CONSCIÊNCIA SOCIAL, SILÁBICA E ALFABÉTICA Valéria Batista \& Mônica Bruna Forte}

Soares \& Maciel (2000) nos mostram a partir dos resumos dessas pesquisas que a escola deve mudar, principalmente ao acolher os diversos modos linguísticos dos falantes que chegam à escola. Essa realidade de acolhimento se agrava quando o foco são as escolas públicas periféricas.

A proposta do método sociolinguístico baseado na alfabetização de Paulo Freire culmina com uma alfabetização que acolhe as diferenças linguísticas e trabalha a partir delas, valorizando o sujeito nas suas diferentes dimensões. Enquanto cidadão, dentro do seu contexto político e social e a partir da sua realidade, ele pode, assim, despertar para a cidadania plena e para a transformação social.

\section{Método de alfabetização de Paulo Freire}

O "Método de Alfabetização" proposto por Paulo Freire é fruto de uma prática que se iniciou nos anos de 1960, no Nordeste brasileiro, com analfabetos rurais que estavam expostos a uma realidade opressora, com muitas limitações sociais e econômicas e diante de muitas necessidades.

\footnotetext{
Primeiro foi feita uma pequena experiência na casa que o MCP conseguiu arrumar numa periferia de Recife. Foram 5 alfabetizandos. Dois saíram, ficaram 3. De lá a equipe realizou as primeiras experiências mais amplas em Angicos e Mossoró, no Rio Grande do Norte, e em João Pessoa, na Paraíba, com o pessoal da CEPLAR. Lavradores do Nordeste foram os primeiros homens a viverem a experiência nova do "círculo de cultura". Foram os primeiros a serem alfabetizados de dentro para fora, através de seu próprio trabalho (BRANDÃO, 2008, p.18).
}

Neste momento nascia o Movimento de Cultura Popular do Recife (MCP), que tinha como objetivo discutir os problemas cotidianos na comunidade de "Poço de Panela"; os três alunos que ficaram aprenderam a ler e a escrever em 30 horas. Num processo em que a proposta é estimular o sujeito a pensar sobre a sua realidade, mas a pensar sobre as normas linguísticas e metodológicas, como a articular sílabas, formando palavras e a composição fonética dessas palavras, o método encaminha o sujeito a ter uma visão de totalidade da linguagem e do mundo.

Brandão (2008) aponta que era tempo da criação dos diversos movimentos. Além do MCP, foram criados os Centros de Cultura Popular do Movimento Estudantil (CPC), do Movimento de Educação de Base da Igreja Católica (MEB), da campanha De Pé no Chão também se Aprende a 
Ler, da Prefeitura de Natal, entre tantos outros. De movimentos semelhantes também em tantos outros lugares do Brasil, surge o sentido das palavras educação popular e cultura popular.

A proposta do Método de Paulo Freire é justamente valorizar a cultura popular e oferecer uma educação que encaminhe o sujeito para a autonomia e para a cidadania, saindo de sua condição de submissão social e política.

Um dos pressupostos do método é a ideia de que ninguém educa ninguém e ninguém se educa sozinho. A educação, que deve ser um ato coletivo, solidário — um ato de amor, dá pra pensar sem susto -, não pode ser imposta. Porque educar é uma tarefa de trocas entre pessoas e, se não pode ser nunca feita por um sujeito isolado (até a autoeducação é um diálogo a distância), não pode ser também o resultado do desejo de quem supõe que possui todo o saber, sobre aquele que, do outro lado, foi obrigado a pensar que não possui nenhum. "Não há educadores puros", pensou Paulo Freire. "Nem educandos." De um lado e do outro do trabalho em que se ensina-e-aprende, há sempre educadores-educandos e educandoseducadores. De lado a lado se ensina. De lado a lado se aprende (BRANDÃO, 2008, p.21).

Freire (1983) estrutura seu método em cinco fases: Levantamento do universo vocabular; Escolha das palavras selecionadas do universo vocabular pesquisado; Criação de situações existenciais; Elaboração de fichas-roteiro; e Elaboração de fichas para a decomposição das famílias fonéticas.

Brandão (2008) destaca: "por acreditar que os materiais prontos, tais como as cartilhas, cartazes e cadernos de exercícios, não faziam parte do mundo vocabular do aluno nem representavam o mundo no qual estava inserido, Paulo Freire pensou num método que fosse construído a partir da sua realidade, por meio do diálogo e do seu saber, portanto um material que retratasse a fala dele". Esse pensamento é determinante para organizar o primeiro momento do método.

Freire (1983) aponta que na primeira fase a proposta é que o professor trabalhe com o levantamento do universo vocabular dos alunos com quem trabalhará. Essa fase constitui num importante momento de pesquisa e de conhecimento da realidade dos alunos, aproximando educador e educando numa relação mais informal e, portanto, mais carregada de sentimentos e emoções. É extremamente importante a anotação das palavras pronunciadas neste momento e de como falam e pronunciam de forma típica algumas palavras - nada pode ser modificado.

Brandão (2008) chama a atenção para o fato de que mesmo sofrendo algumas mudanças no nome da fase, a proposta nunca foi alterada, ou seja, se manteve firme no propósito de valorizar o universo vocabular das pessoas que fariam a formação. 
Esta primeira etapa pedagógica de construção do método foi chamada por Paulo Freire de vários nomes semelhantes: "levantamento do universo vocabular" (em Educação como Prática da Liberdade), "descoberta do universo vocabular" (em Conscientização), "pesquisa do universo vocabular" (em Conscientização $e$ Alfabetização), "investigação do universo temático" (em Pedagogia do Oprimido). De livro para livro algumas palavras mudaram, mas sempre permaneceu viva a mesma ideia: a ideia de que há um universo de fala da cultura da gente do lugar, que deve ser: investigado, pesquisado, levantado, descoberto (BRANDÃO, 2008, p.22).

Nesta primeira fase sugere-se que não se façam questionários nem roteiros. Este é momento da fala do sujeito. Assim, a ideia é ter apenas um caderno de campo em mãos, olhos e ouvidos bem atentos e se possível um aparelho para gravar o que os participantes dizem a respeito de sua vida, casos acontecidos, sobre o trabalho e os modos de ver e compreender o mundo, enfim tudo que acontece no locam que vivem, afirma Brandão (2008), sempre buscando diminuir a distância entre o educador e o educando.

$\mathrm{Na}$ segunda fase, trabalha-se a fala do sujeito, com a escolha das palavras geradoras, a seleção dos termos do universo vocabular pesquisado, tendo em vista alguns critérios: a) sua riqueza fonética; b) dificuldades fonéticas, numa sequência gradativa das menores para as maiores dificuldades; c) teor pragmático da palavra, ou seja, na pluralidade de engajamento da palavra numa dada realidade social, cultural, política.

A respeito da cartilha, Brandão (2008) destaca a incongruência entre as palavras da cartilha e os alunos.

\footnotetext{
Quando o solitário criador de uma cartilha de alfabetização escolhe as palavras-guia para o ensino da leitura, ele lança mão de critérios puramente linguísticos que submete aos pedagógicos. Pode até ser que use critérios afetivos, mas sempre eles serão os seus, pessoais e, para os alunos-alfabetizandos, arbitrários. Por isso, palavras como: Eva, Ivo, ovo, ave, sapato são tão universais quanto vazias. E, na verdade, elas nada precisam dizer nem evocar, porque tradicionalmente alfabetizar tem sido considerado como um trabalho mecânico de ensino de uma habilidade necessária, mas neutra. Uma espécie de mágica que vira mania, ato coletivo compulsivo com que se aprende pelo esforço do simples repetir sem refletir (BRANDÃO, 2008, p. 24).
}

Nesta segunda fase, e de acordo com os critérios, o professor precisa selecionar umas 15 a 25 palavras, lembrando-se de incluir todos os fonemas da Língua Portuguesa, além de incluir as dificuldades de pronúncia e escrita, como $s, s s, c h, x, l h$, e outras dificuldades ortográficas. Oferecer sempre na ordem crescente de dificuldade de leitura e de escrita e da lógica de linguagem na explicação progressiva destas dificuldades. O importante é que as palavras tenham sentido explicito 
e direto com os sujeitos, que estejam carregadas de carga afetiva e de memória crítica, que sejam sentidas e vividas por quem fala e quer aprender a escrevê-la (Brandão, 2008).

$\mathrm{Na}$ terceira fase de criação de situações existenciais, isto é, fase de codificação da descoberta, se continua na escolha dos temas geradores. São situações desafiadoras, codificadas e carregadas dos elementos que serão decodificados pelo grupo com a mediação do educador. São situações locais que, discutidas, abrem perspectivas para a análise de problemas locais, regionais e nacionais.

\footnotetext{
Cada palavra tem o seu uso semântico próprio. Serve para introduzir os fonemas cuja recombinação, feita pelo exercício coletivo de educador e educandos, alfabetiza. Em ordem crescente de dificuldade, cada palavra ajuda a que estes resolvam, com a contribuição daquele, as questões que aos poucos esclarecem os mistérios do ler e escrever.

Mas cada palavra tem também a sua carga pragmática que, vimos, é uma combinação de teor afetivo com peso crítico. "Trabalho", "roçado", "farinha" são palavras carregadas da memória da vida de quem vive no campo, do seu trabalho. Cada palavra esconde muitas falas porque está carregada dos sinais da dor, luta e esperança de quem vive do seu trabalho, passa fome e luta por não perder a pouca terra que lhe resta (Brandão, 2008, p. 26).
}

$\mathrm{Na}$ quarta fase, de elaboração de fichas-roteiro, a proposta é auxiliar os coordenadores de debate no seu trabalho. São fichas que deverão servir como subsídios, mas sem uma prescrição rígida a seguir.

Brandão (2008) afirma que nas experiências pioneiras, no Brasil e no Chile, de Paulo Freire em relação ao Método, o processo de alfabetização não se iniciava com o trabalho de decodificar as palavras geradoras nos círculos de cultura, mas com o pensar juntos a partir de fichas de cultura. As fichas, geralmente desenhos feitos em cartazes - trazidos prontos ou construídos pelas pessoas eram expostas de maneira a provocar os primeiros debates e trocas de ideias sobre o assunto. E juntos passavam a discutir e a introduzir as ideias-base encaminhando-se para as situações existenciais que possibilitassem a apreensão coletiva do conceito de cultura e pudessem conduzir a outros conceitos fundamentais que muitas vezes surgiam e seriam rediscutidos durante todo o trabalho de alfabetização.

$\mathrm{Na}$ quinta fase - de elaboração de ficha para a decomposição das famílias fonéticas destacam-se, na forma de slides ou cartazes, as sílabas dos vocábulos geradores, apresentando a palavra inteira e mais algumas repetições desdobrando os fonemas em pedaços de sílabas. Freire (1983) exemplifica: “Olha aí, gente. Uma casa não tem as suas partes: quarto, cozinha; sala, varanda? Tudo no mundo não tem os seus pedaços? Pois uma palavra também. Tão vendo? 
Benedito tem esses pedaços aí, assim: Be - ne . di - to, Be - ne - di - to, Be - ne - di -to.” A proposta é que o professor leia os fonemas em todas as direções possíveis: horizontal, vertical, salteado, ao acaso, e se algum aluno se sentir à vontade para ler também, devemos deixá-lo seguir no seu ritmo e no seu tempo. Se quiserem criar alguma palavra misturando as sílabas, os fonemas, podemos deixar o grupo livre para que isso ocorra, inclusive incentivando-os a criar novas palavras a partir dos fonemas apresentados.

Só assim a alfabetização cobra sentido. É a consequência de uma reflexão que o homem começa a fazer sobre sua própria capacidade de refletir. Sobre sua posição no mundo. Sobre o mundo mesmo. Sobre seu trabalho. Sobre seu poder de transformar o mundo. Sobre o encontro das consciências. Reflexão sobre a própria alfabetização, que deixa de ser assim algo externo ao homem, para ser dele mesmo. Para sair de dentro de si, em relação com o mundo, como uma criação (FREIRE,1983).

Nestas fases estão contidos momentos de investigação com o levantamento do universo vocabular do sujeito, um momento de tematização capaz de dar sentido e significado às palavras e temas geradores, buscar o significado social para que ele tome consciência do mundo e um terceiro momento de problematização em que aluno e professor buscam superar uma primeira visão ingênua para uma visão crítica do mundo.

\section{Método sociolinguístico: alfabetizar para a consciência social e política}

Mendonça e Mendonça (2006) propõem um método chamado sociolinguístico, em que associam as propostas decorrentes da Psicogênese da Língua escrita, de Emília Ferreiro e Ana Teberosky, com a inclusão das atividades, respeitando os níveis de escrita, que são pré-silábicos, silábicos e alfabéticos, com a proposta de Paulo Freire. Tal proposta surgiu a partir de relatórios de alunos de graduação a respeito de como ocorria - ou não - a aprendizagem dos alunos no período de alfabetização.

As pesquisas de Mendonça e Mendonça (2006) comprovam que, ao sistematizar o ensino, a alfabetização sociolinguística facilita a elaboração e fixação das hipóteses de escrita pelas quais passam até evoluir para a hipótese alfabética. Sendo assim, este método apresenta a possibilidade de alfabetização a partir da possibilidade de reflexão do aprendiz sobre o seu contexto social, suas experiências escolares e seu cotidiano, ou seja, de um ensino capaz de inseri-lo no mundo. 


\section{ALFABETIZAÇÃO NO MÉTODO SOCIOLINGUÍSTICO: UMA PROPOSTA PARA O EXERCÍCIO DA CONSCIÊNCIA SOCIAL, SILÁBICA E ALFABÉTICA Valéria Batista \& Mônica Bruna Forte}

Outra perspectiva que os autores apontam para o método é que a alfabetização em aproximadamente seis meses permite aos professores trabalharem com as crianças a produção textual, interpretação e leitura, de forma a inseri-los maneira mais eficiente no mundo letrado.

Esses mesmos autores destacam que a eficiência do método se encontra no trabalho específico de ensinar as letras (forma, nome e som) e na combinação das letras para a composição das sílabas e, depois, em como unir sílabas para formar palavras, e também, o que são textos e sua função social, isso porque todo o trabalho é desenvolvido a partir de textos reais e extremamente contextualizado, tendo em vista a manutenção das fases iniciais do Método do Paulo Freire.

Afirmam, ainda, que os professores foram levados a pensar que não havia necessidade de ensinar sistematicamente e nem corrigir os alunos. Essa maneira de lidar com o ensino provém de uma possível interpretação equivocada da Psicogênese da Língua escrita, de Ferreiro e Teberosky. Outra crítica é limitar o ensino à prática de apresentação de textos sem a decodificação, forçando os alunos a uma leitura memorizada (ler para eles, pedir que recontem as histórias, apontem palavras e perguntem "o que eles acham" que está escrito, ignorando a necessidade de sistematização do ensino.

Ferreiro e Teberosky (1986) defendem que a aprendizagem da leitura e da escrita não pode se reduzir a um conjunto de técnicas perceptomotoras, nem à vontade ou à motivação, mas que deveria se tratar de uma aquisição conceitual. Esta aquisição conceitual significa a aquisição de conhecimentos baseada na atividade do sujeito em interação com o objeto do conhecimento e no estudo da criança confrontada com esse objeto cultural que constitui a escrita. Dentre os princípios básicos das autoras estaria a criança não identificar a leitura como decifrado; não identificar escrita como cópia de um modelo externo; e não identificar progressos na conceitualização com avanços no decifrado ou na exatidão da cópia gráfica.

Desta forma, Ferreiro e Teberosky (1986) propõem como trajetória na construção do Sistema de Escrita os seguintes níveis: distinção entre o modo de representação nos níveis icônico e não icônico; construção das formas de diferenciação da escrita, considerado como nível présilábico; e a fonetização da escrita, entendido como o nível silábico até o nível alfabético.

Mendonça e Mendonça (2006) propõem para o método sociolinguístico algumas fases da alfabetização: $1^{\text {a }}$ : codificação da palavra geradora (leitura de mundo); $2^{\mathrm{a}}$ : decodificação da palavra geradora, que seria uma releitura da realidade expressa, por meio da crítica e discussão, com subsídios de textos escritos sobre o conhecimento universal acumulado. Neste momento, sugerem atividades didáticas do nível pré-silábico, em diferentes suportes de textos (parlendas, música, poesia, rótulos); $3^{\mathrm{a}}$ : análise e síntese das palavras inteiras e de suas letras iniciais, mediais e finais e 
no domínio da associação entre letras e imagens e localização de palavra geradora escrita no texto gerador. Ainda nesta fase, faz-se a apresentação da família silábica e apresenta atividades do nível silábico, com exercícios que explorem sílabas iniciais, mediais e finais na composição de palavras; e uso de dominós silábicos para formar palavras; $4^{\text {a }}$ : fixação da leitura e da escrita com atividades didáticas do nível alfabético: Leitura e escrita das palavras compostas na síntese das sílabas; ditado de palavras e frases; caça-palavras; palavras cruzadas; transposição oral e escrita do dialeto do aluno para o dialeto padrão; interpretação, produção de frases e textos com significado.

Enfim, apresentamos o método sociolinguístico como uma possibilidade de alfabetizar as crianças de maneira contextualizada, de forma sistematizada com o ensino das letras, sílabas e palavras, para, então, trabalhar interpretação e produção de textos.

\section{Considerações finais}

Os resultados da pesquisa indicam que para atingir o modelo sociolinguístico de alfabetização deve-se reinventar o processo de ensino da leitura e da escrita a partir de uma perspectiva social. Só assim, serão possíveis intercâmbios interacionais do sujeito com o seu contexto social e político, sem deixar de trabalhar o específico da língua: a codificação e a decodificação das letras, sílabas, palavras, etc. O método propõe entender a aprendizagem como um construto permeado de valores histórico-sociais capaz de encaminhar o sujeito à apreensão de conceitos e interpretações a partir da própria realidade, influenciando sua percepção e compreensão de mundo, como nos aponta Paulo Freire.

Depreende-se deste trabalho que as teorias linguísticas e psicológicas sozinhas não conseguiriam explicar as condições sociais e ambientais para o aprendizado das habilidades específicas de ler e escrever. O ler e o escrever têm como base o domínio das correspondências entre grafemas e fonemas, para a exercitação da consciência silábica e alfabética, indispensável para a aprendizagem da leitura e da escrita, mas deve ter como proposta levar o sujeito para além de sua realidade. A alfabetização, ao integrar os fundamentos sociológicos a partir da análise discursiva, dos aspectos dialógicos e da interação verbal, o encaminha para uma leitura do mundo, transformando sua consciência ingênua em consciência crítica.

Esta pesquisa quis ampliar o debate sobre a alfabetização e apresentar a possibilidade de um ensino que está para além da simples alfabetização, ou seja, um ensino capaz de promover a inserção do sujeito no seu contexto social e político, na sua realidade, despertando-o para a 
cidadania e, consequentemente, para sua transformação social. O que se procurou defender aqui, com base nos autores citados, é uma alfabetização conscientizadora, numa perspectiva crítica e reflexiva do sujeito, sem desconsiderar a importância de princípios linguísticos básicos da fala, da escrita e da leitura como base para uma alfabetização de fato.

\section{Referências bibliográficas}

BALARINI, M. de M.. Alfabetização: uma interpretação sociolingüística. Dissertação (Mestrado) Universidade Federal do Espírito Santo. Vitória, 1987. 278 p.

BRANDÃO, C. R.. O que é método Paulo Freire. 29a.ed. São Paulo: Brasiliense, 2008.

CAGLIARI, Luiz Carlos. Alfabetização e Lingüística. São Paulo: Scipione, 1999.

FERREIRO, E.; TEBEROSKY, A. Psicogênese da língua escrita. Porto Alegre: Artes Médicas, 1986.

FREIRE, P.. Educação como prática da liberdade. 14. ed. Rio de Janeiro: Paz e Terra, 1983.

GUIMARÃES, M. I. de O. A validade da mensagem nas classes de alfabetização. Dissertação (Mestrado em Letras) - Universidade Católica do Paraná. Curitiba, 1979. 321 p.

MENDONÇA,O.S.; MENDONÇA, O.C. Alfabetização reinventada: o método sociolingüístico consciência social, silábica e alfabética em Paulo Freire. Revista ACOALFAplp: Acolhendo a Alfabetização nos Países de Língua portuguesa, São Paulo, ano 1, n. 1, 2006. Disponível em: http://www.redalyc.org/articulo.oa?id=87910106 . Acesso em 15.06.2015.

. Alfabetização método sociolingüístico: Consciência social, silábica e alfabética em Paulo Freire. 2.ed. São Paulo: Cortez, 2008.

MORIN, E. A cabeça bem-feita: repensar a reforma, reformar o pensamento. Tradução de Eloá Jacobina. 9. ed. Rio de Janeiro: Bertrand Brasil, 2004.

MORTATTI, Maria do Rosário Longo. História dos métodos de alfabetização no Brasil. Conferência proferida durante o Seminário "Alfabetização e letramento em debate", promovido pelo Departamento de Políticas de Educação Infantil e Ensino Fundamental da Secretaria de Educação Básica do Ministério da Educação, realizado em Brasília, em 27/04/2006. Disponível em: http://portal.mec.gov.br/seb/arquivos/pdf/Ensfund/alf_mortattihisttextalfbbr.pdf. Acesso em: 16 . junho..2015.

NOZAKI, I..Código e desigualdade: estudo experimental de sociolingüística aplicado à tecnologia educacional. Dissertação (Mestrado) Universidade Estadual do Rio de Janeiro. Rio de Janeiro, 1986. 292 p. 
SILVA, M. de N. da C.. Para repensar a alfabetização: um estudo introdutório. Campinas, 1987. 109 p. Dissertação (Mestrado) Faculdade de Educação, Universidade Estadual de Campinas.

SOARES, M.B. ; MACIEL, F.(orgs.). Alfabetização. MEC/Inep. Comped, 2000. 